\title{
SISTEM PENDUKUNG KEPUTUSAN PERENCANAAN AKADEMIK DENGAN METODE BEST FIRST SEARCH (Studi Kasus di Sekolah Tinggi Teknologi Adisutjipto)
}

\author{
Atika Rina, Anton Setiawan Honggowibowo, Nur Cahyani Dewi Retnowati \\ Teknik Informatika STTA Yogyakarta \\ informatika@stta.ac.id
}

\begin{abstract}
With the rapid growth in current technology, academic systems in higher education has been computerized. Academic who has a computerized system is considered more effective. The computerized system has can be used to plan the academic activities of students for taking Strata 1 at the College of Technology Adisutiipto. The system uses Decision Support System (DSS) to give some conditions on Best First Search (BFS) method so that the method can be used in a subsequent advisory list of the best courses in accordance with the terms that have been obtained, which will help students in making academic decisions. Of the BFS method, students are given a solution in the form of a list next semester of courses that can be taken in accordance with the terms obtained from the previous semester in the form of Performance Index and the solution was given until the end of the lecture the student and provides the calculation of the total cost of each semester.
\end{abstract}

Keywords: Plan, Decision Support System (DSS), Best First Search Method

\begin{abstract}
Abstrak
Dengan berkembang pesatnya teknologi pada saat ini, sistem akademik di perguruan tinggi telah terkomputerisasi. Sistem akademik yang telah terkomputerisasi ini dinilai lebih efektif Sistem yang telah terkomputerisasi tersebut dapat dimanfaatkan untuk merencanakan kegiatan akademik mahasiswa selama menempuh Strata 1 pada Sekolah Tinggi Teknologi Adisutjipto. Sistem ini menggunakan Sistem Pendukung Keputusan (SPK) untuk memberi beberapa syarat pada metode Best First Search (BFS) sehingga metode dapat digunakan dalam pemberian saran daftar matakuliah selanjutnya yang terbaik yang sesuai dengan syarat yang telah didapat, yang nantinya dapat membantu mahasiswa dalam pengambilan keputusan akademiknya.Dari metode BFS tersebut, mahasisza diberikan solusi berupa daftar matakuliah semester selanjutnya yang dapat diambil sesuai dengan syarat yang diperoleh dari semester sebelumnya yaitu berupa Index Prestasi dan solusi tersebut diberikan hingga akhir perkuliahan mahasiswa tersebut serta memberikan perhitungan total biaya yang dikeluarkan setiap semesternya.
\end{abstract}

Kata kunci : Rencana, Sistem Pendukung Keputusan (SPK), metode Best First Search 


\section{Pendahuluan}

Sistem akademik yang telah terkomputerisasi ini dinilai lebih efektif. Seperti halnya dalam proses pengisian Kartu Rencana Studi (KRS). Mahasiswa mengisi KRS dengan cara memilih mata kuliah yang tersedia pada sistem pengisian KRS. Sistem secara otomatis menyediakan mata kuliah yang tersedia pada semester tersebut dan langsung membatasi jumlah Satuan Kredit Semester (SKS) yang dapat diambil oleh seorang mahasiswa pada semester tersebut sesuai dengan Indeks Prestasi (IP) yang diperoleh mahasiswa tersebut pada semester sebelumnya.

Pada kasus ini, latar belakangnya adalah berawal dari permasalahan yang dihadapi mahasiswa jurusan Teknik Informatika dalam memanajamen waktu tempuh kuliah untuk menyelesaikan kuliahnya tepat pada waktunya, dalam hal ini adalah untuk menempuh pendidikan Strata 1 (S1) tepat waktu, yaitu selama empat tahun. Kebanyakan mahasiswa Jurusan Teknik informatika hanya merencanakan

untuk menyelesaikan pendidikannya tersebut tepat waktu. Namun pada pelaksanaannya, terkadang rencana tersebut tidak dapat direalisasikan karena terhambat oleh suatu permasalahan, seperti IP yang rendah, atau bahkan mengambil cuti kuliah untuk berkerja agar dapat membiayai kuliahnya tersebut.

Dari beberapa contoh permasalahan yang dihadapi para mahasiswa jurusan Teknik Informatika tersebut, maka dibuatlah solusi dengan menggunakan aplikasi yang dapat merencanakan kegiatan akademik selama menempuh pendidikan di Sekolah Tinggi Teknologi Adisutjipto. Perencanaan tersebut meliputi mata kuliah apa saja yang dapat diambil berdasarkan IP yang diperoleh di semester sebelumnya, nilai apa saja yang harus diperoleh untuk mendapatkan IP yang bagus untuk semester tersebut, berapa nilai Indeks Prestasi Kumulatif (IPK) yang ingin diperoleh, berapa jumlah biaya yang di perlukan untuk menempuh kuliah tersebut dan juga dapat memberikan alternative pilihan kepada mahasiswa tentang apa yang akan mahasiswa tersebut lakukan jika mendapatkan nilai yang kurang memuaskan.

Jadi, sistem yang akan dibuat ini diharapkan dapat meningkatkan tingkat kelulusan tepat waktu karena mahasiswa itu sendiri merasa termotivasi untuk merealisasikan rencana akademik yang telah ia buat sehingga dapat lulus dengan IPK yang bagus.

\section{Landasan Teori}

\subsection{Sistem Pendukung Keputusan}

Sistem adalah suatu kumpulan elemen-elemen yang saling berinteraksi untuk mencapai suatu tujuan tertentu. Suatu sistem terdiri dari jumlah komponen yang saling berinteraksi, bekerja sama yang membentuk satu kesatuan.

Jadi Sistem Pendukung Keputusan adalah sebuah sistem yang dimaksudkan untuk mendukung para pengambil keputusan dalam pengambilan keputusan pada situasi yang semiterstruktur dan situasi yang tidak terstruktur, dimana tak seorangpun tahu secara pasti bagaimana keputusan seharusnya dibuat. 


\subsection{Metode Best First Search}

Metode Best First Search memperkenankan pencarian dengan mengunjungi node yang ada di level yang lebih rendah jika ternyata node pada level yang lebih tinggi ternyata memiliki nilai heuristik yang buruk.

Pada setiap langkah proses pencarian best first, pilih node yang paling menjanjikan sesuatu. Hal ini dilakukan dengan menerapkan fungsi heuristik yang memadai pada setiap simpul tersebut. Kemudian kembangkan node yang - dipilih dengan menggunakan aturan tertentu untuk menghasilkan penggantinya.

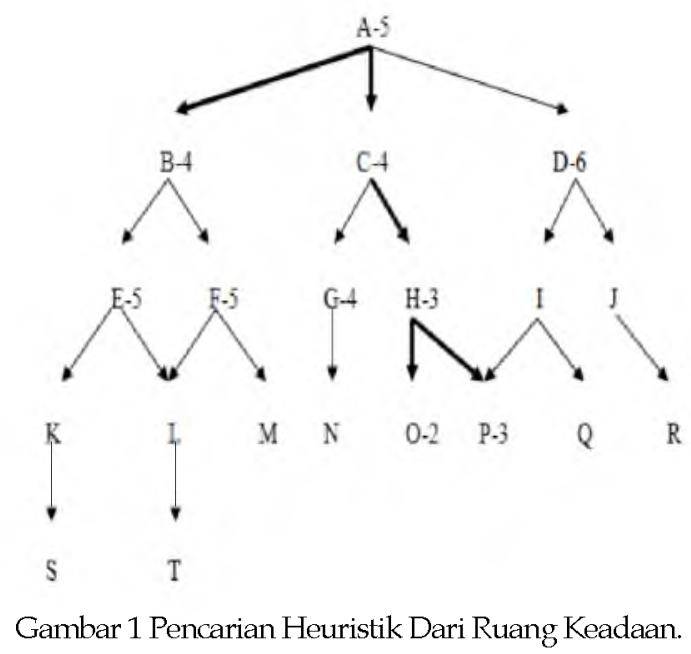

\section{Analisis dan Perancangan Sistem}

Analisis merupakan pengkajian secara terperinci dan detail mengenai sesuatu yang dilaksanakan untuk mengetahui lebih jauh mengenai obyek yang diteliti secara mendalam. Tujuan dari analisis ini adalah agar dapat diperoleh gambaran secara umum mengenai analisis kebutuhan yang nantinya akan membantu proses pembangunan sebuah sistem.

\subsection{Perancangan Diagram Alir Data}

Diagram Alir Data yang disingkat DAD atau DFD (Data Flow Diagram) merupakan suatu model logika data atau proses yang dibuat untuk menggambarkan dari mana asal data dan ke mana tujuan data yang keluar dari sistem, dimana data disimpan, proses apa yang menghasilkan data tersebut dan interaksi antara data yang tersimpan dan proses yang dikenakan pada data tersebut. Dimana dalam penggambarannya, Diagram Alir Data menggunakan notasi-notasi untuk menggambarkan arus dari data sistem, yang penggunaannya sangat membantu untuk memahami sistem secara logika, tersruktur dan jelas sehingga dapat membantu dalam menggambarkan atau menjelaskan sistem yang sedang berjalan logis. Sehingga dengan DAD ini dapat diketahui dimana data disimpan dan bagaimana transformasi datanya.

\subsubsection{Diagram Konteks}

Diagram konteks pada gambar 2 adalah diagram level tertinggi dari DAD (Diagram Alir Data) yang menggambarkan hubungan sistem dengan lingkungan luarnya. Pada Sistem 
Pendukung Keputusan (SPK) Perencanaan Akademik ini, sistem berhubungan dengan Jurusan dan mahasiswa.

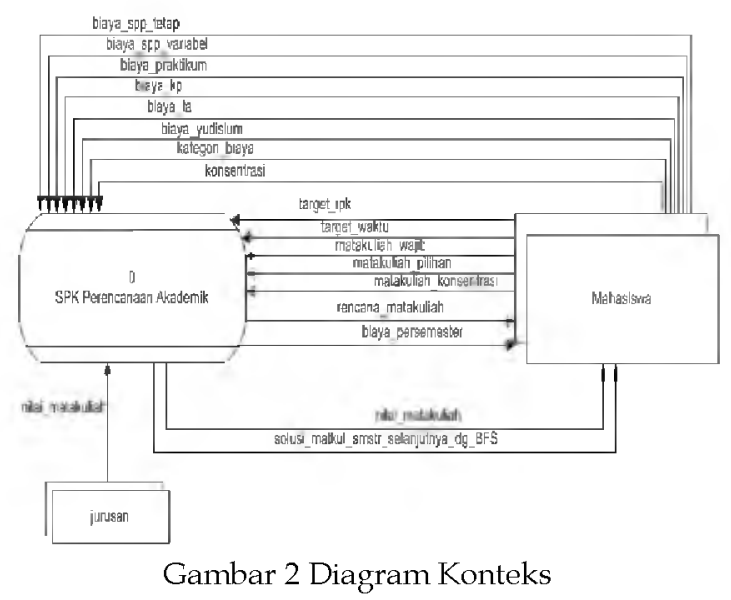

\subsubsection{Dekomposisi}

Dekomposisi merupakan penjabaran dari diagram konteks yang berisi subsistem, proses dan subproses. Pada gambar 3, penjabaran diagram konteks dilakukan dengan membagi sistem utama menjadi Pengisian data dan Lihat data. Pengisian data terbagi menjadi dua, yaitu hitung biaya dan perencanaan akademik. Sedangkan Lihat data terbagi menjadi Hasil rencana dan Perencanaan matakuliah semester berikutnya dengan Best First Search.

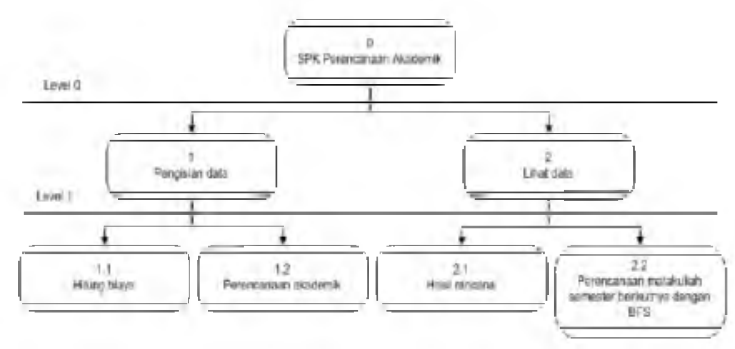

Gambar 3 Dekomposisi SPK Perencanaan Akademik

\subsubsection{DAD Level 0}

Pada level ini, akan terlihat bagaimana secara garis besar alur data yang terjadi pada program. Pada level ini, para entitas yaitu mahasiswa dan jurusan memiliki hubungan dengan para Proses data yaitu pengisian data dan Lihat data. Hubungan tersebut terdapat pada Gambar 4 berikut ini. 


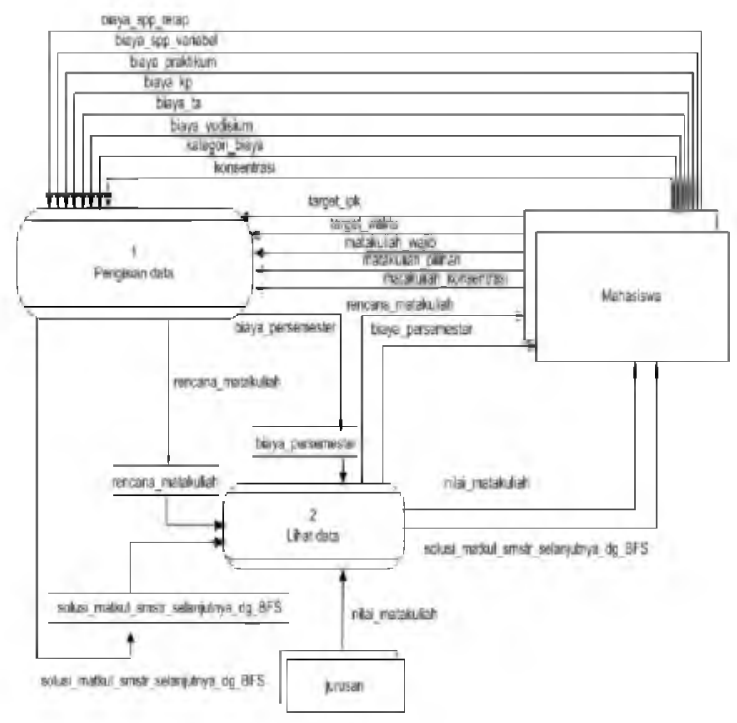

Gambar 4 DAD Level 0

\subsubsection{DAD Level 1}

Pada DAD level 1, sistem terbagi menjadi dua proses yaitu DAD Level 1 Proses 1 Pengisian Data dan DAD Level 1 Proses 2 Lihat Data. Gambar 5 adalah DAD Level 1 Proses 1 Pengisian Data dan Gambar 6 adalah DAD Level 1 Proses 2 Lihat Data.

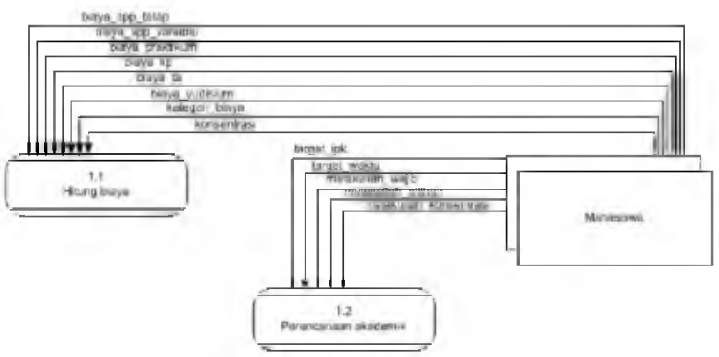

Gambar 5 DAD level 1 Proses 1 Pengisian Data oleh Mahasiswa

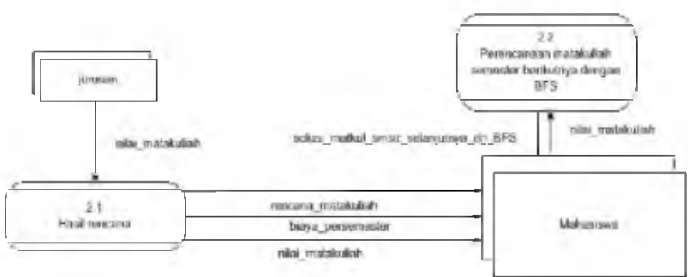

Gambar 6 DAD Level 1 Proses 2 Lihat Data oleh Mahasiswa

\subsection{Flow Chart}

Flow Chart merupakan cara untuk menggambarkan alur sistem program. Perintah yang dituliskan dalam simbol, memperlihatkan aliran proses dari sebuah bagian program kebagian program lainnya.

Alur pada program ini berawal dengan menjalankan program, kemudian masuk pada menu Login dan setelah login maka akan masuk pada menu Input Biaya. Setelah memasukkan nilai pada Text Box yang tersedia, pilih tombol simpan. Setelah memilih tombol simpan, maka akan menuju menu input target. 
Jika sebelumnya pernah menyimpan data pada Text Box tersebut, maka akan muncul menu yaitu Menu Utama dan jika memilih menu ini maka akan langsung masuk pada Menu Utama yaitu input Matakuliah.

Setelah memilih dan mengisi menu input kategori dan menyimpannya, selanjutnya akan menuju menu target rencana. Setelah mengisi dan menyimpan data pada menu target rencana, maka akan menuju menu konfirmasi rencana.

Setelah itu akan menuju menu utama yaitu menu input matakuliah. Setelah menginputkan matakuliah dan menyimpannya, maka akan menuju menu rencana akademik. Target nilai dapat diubah sesuai rencana pengguna.

Untuk melihat realisasi dari rencana yang ditetapkan, maka dapat memilih menu realisasi rencana. Pada menu ini, akan ditampilkan nilai yang diperoleh. Jika nilai yang diperoleh adalah selain nilai A dan B, maka akan muncul tombol remedial, mengulang dan abaikan. Terdapat pula tombol solusi, yaitu adalah target rencana terbaik selanjutnya yang dipilihkan oleh program berdasarkan nilai IP yang diperoleh. Tombol ganti rencana adalah untuk mengubah seluruh rencana, sedangkan tombol keluar adalah untuk keluar dari program. Jika keluar dari program, maka program selesai

Gambar 7 merupakan flow chart dari program Sistem Pendukung Keputusan Perencanaan Akademik.

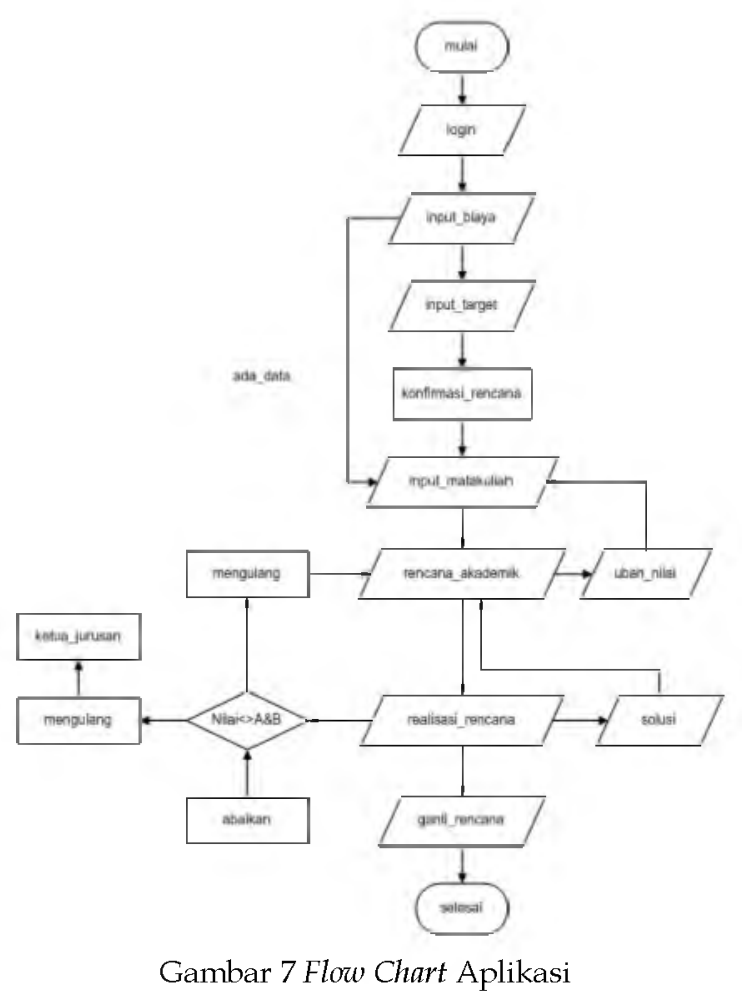




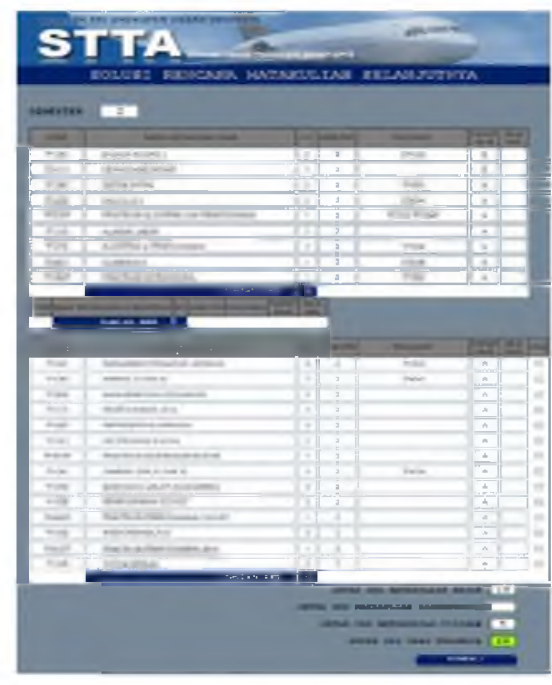

Gambar 8 Form Solusi

Pada program ini pengaplikasian metode Best First Search terdapat pada form realisasi rencana. Pada form realisasi rencana, metode tersebut teraplikasikan dengan cara memberikan solusi yang berbeda-beda jika dipilih tombol "SOLUSI".

Pada dasarnya, metode ini adalah pencarian rute terpendek yang terbaik. Untuk pencarian rute terpendek, pada kasus ini memiliki syarat tertentu yaitu IP yang telah didapat pada semester sebelumnya. Dari IP tersebut, program akan menentukan kuota SKS yang diperoleh untuk mengambil maksimum SKS pada matakuliah semester selanjutnya.

Dari kuota tersebut, program akan langsung menyarankan kombinasi matakuliah pada semester selanjutnya yang memenuhi maksimum kuota yang tersedia. Jika kuota yang tersedia adalah 24 SKS, maka program akan langsung memunculkan kombinasi matakuliah pada semester selanjutnya yang mencapai maksimum 24 sks. Sehingga pada akhirnya penentuan jalur pada kasus ini adalah dengan pengarahan matakuliah yang diambil pada semester selanjutnya.

Gambar 9 adalah alur pencarian best first search (BFS) yang teraplikasikan pada program Sistem Pendukung Keputusan (SPK ) Perencanaan Akademik. Pada kasus ini, mahasiswa selalu mendapatkan IP lebih dari 3.00 sehingga kuota yang didapatkan adalah 24 sks.

Apabila mahasiswa telah menyelesaikan semester 1, maka untuk melihat metode BFS terletak dimana, adalah pada tombol SOLUSI. Jadi, setelah seluruh nilai pada semester 1 keluar, maka akan muncul IP. IP tersebut merupakan syarat yang digunakan oleh sistem untuk menentukan matakuliah pada semester selanjutnya. Jadi untuk melihat letak dari metode pada program ini, maka mahasiswa harus memiliki sebuah syarat yaitu harus menyelesaikan dahulu semester yang sedang diambil, sehingga nantinya seluruh nilai pada semester tersebut keluar seluruhnya, barulah dapat melihat solusi yang ditawarkan atau node mana yang harus diambil. 


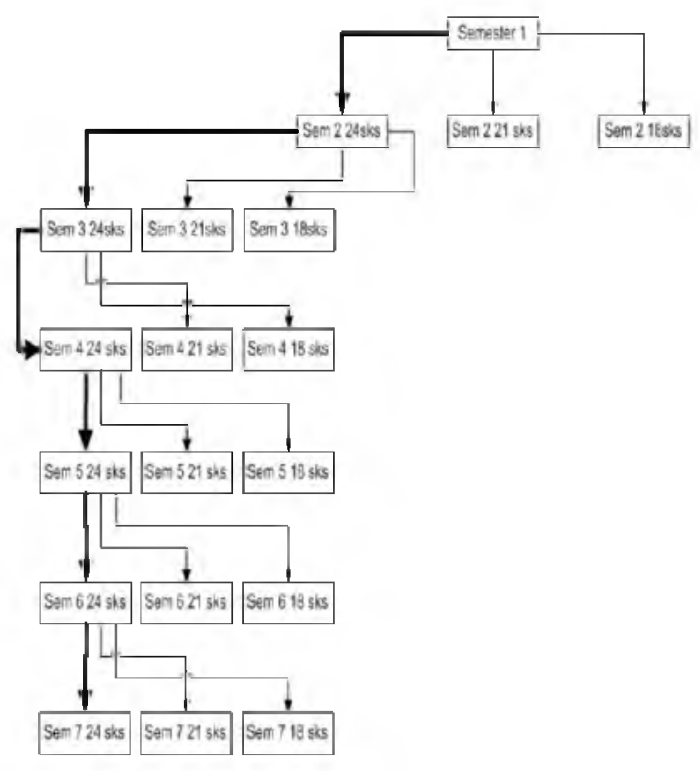

Gambar 9 Alur BFS SPK Perencanaan Akademik

Pada Gambar 9, Alur BFS dibuat berdasarkan nilai yang didapat dari sampel, yaitu seorang mahasiswi STTA Jurusan Teknik Informatika dengan NIM 09030001.

Sampel tersebut pada semester 1 mendapatkan IP 3.74 yang mana IP tersebut lebih dari 3.00 sehingga mendapatkan jatah SKS pada semester selanjutnya adalah 24 SKS, sehingga ketika dipilih tombol SOLUSI pada menu realisasi rencana, maka solusi yang keluar mengarahkan sampel untuk mengambil susunan matakuliah dengan jumlah SKS adalah 24 SKS pada semester 2. Pada tahap ini, alur BFS mengalir dari titik pangkal yaitu semester 1, menuju pada node semester 2 dengan 24 SKS. Sekalipun jatah SKS yang dipeoleh tersebut memungkinkan untuk mengambil 21 SKS ataupun 18 SKS, namun program mengarahkan sampel tersebut pada node dengan jatah SKS maksimum yaitu semester 2 dengan 24 SKS, sehingga mempercepat waktu tempuh perkuliahan sampel tersebut.

Pada semester 2, sampel tersebut memperoleh IP 3.63, sehingga memiliki jatah SKS maksimum pada semester selanjutnya adalah 24 SKS, maka ketika sampel tersebut memilih tombol solusi, maka akan muncul susunan matakuliah pada semester 3 dengan SKS maksimum adalah 24 SKS. Sehingga node selanjutnya berjalan dari node semester 2 dengan 24 SKS menuju node semester 3 dengan 24 SKS.

Pada semester 3, sampel memperoleh IP 3.78. Dengan IP tersebut, jatah SKS maksimum yang dapat diambil pada semester 4 adalah 24 SKS, sehingga daftar matakuliah semester 4 pada tombol solusi mengarahkan sampel pada node semester 4 dengan 24 SKS. Node bergerak dari semester 3 dengan 24 SKS menuju node semester 4 dengan 24 SKS.

Pada semester 4, sampel memperoleh IP 3.88 yang mana SKS maksimum untuk semester 5 adalah 24 SKS, sehingga ketika sampel memilih tombol solusi, program langsung mengarahkannya pada node semester 5 dengan 24 SKS.

Pada semester 5, sampel memperoleh IP 3.65 yang mana SKS maksimum untuk semester 6 adalah 24 SKS, sehingga ketika sampel memilih tombol solusi, program langsung mengarahkannya pada node semester 6 dengan 24 SKS. 
Pada semester 6, sampel memperoleh IP 3.67 yang mana SKS maksimum untuk semester 7 adalah 24 SKS, sehingga ketika sampel memilih tombol solusi, program langsung mengarahkannya pada node semester 7 dengan 24 SKS.

Karena sampel saat ini baru menempuh semester 7, maka Alur BFS SPK Perencanaan Akademik BFS dari program yang dijalankan sampel berhenti sementara pada node semester 7 dengan 24 SKS. Alur akan berjalan kembali menuju node selanjutnya, apakah akan menuju node semester 8 dengan 24 SKS, node semester 8 dengan 21 SKS, atau node semester 8 dengan 18 SKS apabila sampel telah memiliki IP pada semester 7 .

\section{Kesimpulan}

1. Metode Best First Search (BFS) dapat mendukung Sistem Pendukung Keputusan Perencanaan Akademik.

2. Dari hasil penelitian mengenai aplikasi ini adalah baik dan menuju baik sekali dari penggunanya.

3. Sehingga dapat disimpulkan bahwa aplikasi dapat digunakan untuk membantu penggunanya untuk merencanakan kegiatan akademik selama menempuh perkuliahan di Sekolah Tinggi Teknologi Adisutjipto seperti memprediksi biaya, IPK yang akan diperoleh serta total biaya yang dibutuhkan selama menempuh perkuliahan di STTA.

Aplikasi ini masih dapat dikembangkan, antara lain :

1. Aplikasi ini dapat dikembangkan sebagai sarana penginputan KRS otomatis.

2. Aplikasi ini dapat dikembangkan untuk jurusan lain.

\section{Daftar Pustaka}

[1] Agustian, H., 2012, Sistem Pendukung Keputusan Pemilihan Guru Teladan Dengan Simple Additive Weighting Method (SAW) Studi Kasus Di SMA Angkasa Yogyakarta, Jurnal Compiler, Volume I Nomor 1 Mei 2012 ISSN: 2252-3389, Sekolah Tinggi Teknologi Adisutjipto, Yogyakarta.

[2] Anonim, Buku Panduan Akademik Sekolah Tinggi Teknologi Adisutjipto (STTA) T.A. 20112012, Sekolah Tinggi Teknologi Adisutjipto, Yogyakarta.

[3] Desiani, A., 2006, Konsep Kecerdasan Buatan, Penerbit Andi, Yogyakarta.

[4] Dwipayani, M. I., 2012, Sistem Pendukung Keputusan Penentuan Cuti Pegawai Menggunakan Metode Technique For Order Preference By Similarity To Ideal Solution Studi Kasus Di Kantor Pelayanan Perbendaharaan Negara Yogyakarta, Jurnal Compiler, Volume I Nomor 1 Mei 2012 ISSN: 2252-3389, Sekolah Tinggi Teknologi Adisutjipto, Yogyakarta.

[5] Syafii, M., 2005 Panduan Membuat Aplikasi Database Dengan PHP 5 MySQL PostgreSQL Oracle, Penerbit Andi, Malang.

[6] Turban, E., dkk., 2005, Decision Support Systems and Intelligent System, Penerbit Andi, Yogyakarta.

[7] Wiswakarma, K., 2010, 9 Langkah Menjadi Master Framework Codeigniter, Loka Media. Bekasi. 